\title{
Oxidative stress marker 8-hydroxyguanosine is more highly expressed in prostate cancer than in benign prostatic hyperplasia
}

\author{
SHINJI OHTAKE ${ }^{1,2}$, TAKASHI KAWAHARA ${ }^{1,2}$, YUKARI ISHIGURO ${ }^{2}$, TEPPEI TAKESHIMA ${ }^{2}$, \\ SHINNOSUKE KURODA ${ }^{2}$, KOJI IZUMI ${ }^{2}$, HIROSHI MIYAMOTO ${ }^{3}$ and HIROJI UEMURA ${ }^{2}$ \\ ${ }^{1}$ Department of Urology, Yokohama City University Graduate School of Medicine, Yokohama, Kanagawa 236-0004; \\ ${ }^{2}$ Department of Urology and Renal Transplantation, Yokohama City University Medical Center, Yokohama, \\ Kanagawa 232-0024, Japan; ${ }^{3}$ Departments of Pathology and Laboratory Medicine, Urology, \\ and Oncology, University of Rochester Medical Center, Rochester, NY 14627, USA
}

Received March 19, 2018; Accepted July 2, 2018

DOI: $10.3892 / \mathrm{mco} .2018 .1665$

\begin{abstract}
Oxidative stress is a primary cause of vascular endothelial damage. In the prostate, ischemia increases the levels of reactive oxygen species, growth factors and cytokines, and induces the development of angiogenesis, which results in cancer progression. The expression levels of an oxidative stress marker, 8-hydroxyguanosine (8-OHdG), were compared between prostate cancer and non-neoplastic prostate tissues. A prostate tissue microarray composed of 10 cases of prostatic adenocarcinoma and 70 cases of benign prostatic hyperplasia was immunohistochemically stained for 8-OHdG. All cases expressed 8-OHdG. The levels of 8-OHdG expression in prostatic cancer $(30.0 \%$ moderate and $70.0 \%$ strong) were significantly higher than those in benign prostatic hyperplasia $(71.4 \%$ moderate and $28.6 \%$ strong; $(\mathrm{p}<0.01)$. Notably, 8 -OHdG is expressed more highly in prostate cancer tissues in comparison to benign prostate tissues.
\end{abstract}

\section{Introduction}

Oxidative stress is a chief cause of vascular endothelial damage. It increases the levels of reactive oxygen species, which subsequently induces vascular endothelial dysfunction via the inhibition of nitric oxide production (1).

In the prostate, ischemia increases the levels of reactive oxygen species, growth factors, and cytokines, and induces the development of angiogenesis, resulting in cancer progression (2). Recent studies, using a prostate hyperplasia mouse model have demonstrated that ischemia in the prostatic

Correspondence to: Dr Takashi Kawahara, Department of Urology and Renal Transplantation, Yokohama City University Medical Center, 4-57 Urafune-cho, Minami-ku, Yokohama, Kanagawa 232-0024, Japan

E-mail: takashi_tk2001@yahoo.co.jp

Key words: oxidative stress, 8-hydroxyguanosine, prostate cancer, benign prostatic hyperplasia, tadalafil epithelium induces oxidative stress, resulting in cell proliferation involved by inflammatory cytokines and several growth factors $(3,4)$.

These findings indicate that oxidative stress plays an important role in the prostate. No report has described the tissue 8-hydroxyguanosine (8-OHdG) expression in prostatic specimens. In the present study, we compared the expression levels of an oxidative stress marker 8-hydroxyguanosine between prostate adenocarcinoma and non-neoplastic prostate tissues.

\section{Materials and methods}

Immunohistochemistry was performed, as described previously (5) in sections from a prostatic tissue microarray composed of 10 cases of prostatic adenocarcinoma and 70 cases of non-neoplastic prostate (PR804; US Biomax, Rockville, MD, USA). This company obtained informed consent (https://www.biomax.us/FAQs,Q10) Briefly, $5-\mu \mathrm{m}$-thick slides were dewaxed with xylene, hydrated with gradient ethanol, and microwaved at high level for $2 \mathrm{~min}$., followed by $30 \mathrm{~min}$. microwaved at middle-low levels for heat antigen retrieval (Target Retrieval Solution pH9, Dako, Carpinteria, CA, USA). After 3\% hydrogen peroxidase block, the samples were incubated overnight at $4^{\circ} \mathrm{C}$ with a primary antibody to anti-8-OHdG (ab48508, diluted to 1:200; Abcam, Cambridge, MA, USA) and a broad-spectrum secondary antibody (Histostain-SP kit; Invitrogen, Grand Island, NY, USA) for $2 \mathrm{~h}$ (Table I). The slides were then examined by a single pathologist (HM) blinded to sample identify. The score of immunoreactivity was determined by multiplying the percentage of immunoreactive cells $(0 \%=0 ; 1-10 \%=1$; $11-50 \%=2 ; 51-80 \%=3 ; 81-100 \%=4)$ by staining intensity $($ negative $=0$; weak $=1$; moderate $=2$; strong $=3$ ). The immunohistochemical scores (ranging from 0 to 12) were considered negative $(0 ; 0-1)$, weakly positive $(1+; 2-4)$, moderately positive (2+; 6-8), and strongly positive (3+;9-12) for 8-OHdG expression (5).

The 8-OHdG expression was analyzed by chi-square test using the Graph Pad Prism software program (Graph Pad Software, La Jolla, CA, USA). 


\section{Results}

We immunohistochemically stained for $8-\mathrm{OHdG}$ in a prostate tissue microarray. Positive signals were detected predominantly in cytoplasm of epithelial cells as well as in nucleus of epithelial cells only in a few cases (Fig. 1). 8-OHdG was immunoreactive in all 10 prostatic adenocarcinomas, including $3(30 \%)$ cases with moderate $(2+)$ expression and $7(70 \%)$ cases with strong (3+) expression. Similarly, $8-\mathrm{OHdG}$ was moderately and strongly positive in $50(71.4 \%)$ and $20(28.6 \%)$ cases of benign prostatic hyperplasia (Table II). Thus, the levels of $8-\mathrm{OHdG}$ expression in prostatic adenocarcinoma tissue specimens were significantly higher than those in non-neoplastic prostate tissue specimens $(\mathrm{P}<0.01)$.

\section{Discussion}

Our results showed that prostate adenocarcinoma showed higher 8-OHdG expression than non-neoplastic prostate tissue. Miyake et al showed that prostate cancer patients had significantly higher levels of urine 8-OHdG/Cre than those without cancer (6). In patients with prostate cancer, urine 8-OHdG/Cre levels were not markedly different before and after radical prostatectomy. In contrast, their levels were decreased significantly after androgen deprivation therapy. These findings indicate that androgen deprivation therapy reduces oxidative stress.

The detailed mechanism underlying the cancer progression induced by $8-\mathrm{OHdG}$ is still unknown. Guanine is easily damaged by anti-oxidant stress, resulting in a change to 8-OHdG. 8-OHdG is structurally stable and widely used as an oxidant-stress biomarker $(6,7) \cdot \mathrm{H}_{2} \mathrm{O}_{2}$ has also been shown to increase $8-\mathrm{OHdG}$ in a time-dependent manner in prostatic epithelial cells, which is one potential mechanism underlying cancer progression, presumably due to continuous anti-oxidant damage $(8,9)$. Based on these findings, oxidant stress produced $8-\mathrm{OHdG}$ in prostate tissue, resulting in the time-dependent accumulation of $8-\mathrm{OHdG}$ and subsequent carcinogenesis due to the damage of DNA. Wu and Ni showed the correlation between 8-OHdg and carcinogenesis and speculated that hypomethylation and regional hypermethylation contribute to carcinogenesis (10). In gastric cancer, a correlation has been reported between gastric cancer and cytotoxin-associated genes that induces cancer progression. However, the detailed mechanisms are still unknown (11). While further studies are needed, the findings from the present study suggest that 8-OHdG might be a candidate tumor marker for detecting prostate cancer.

Tadalafil, a PDE-5 inhibitor, inhibits cGMP in smooth muscle cells and induces reflexes smooth muscle $(12,13)$. Gotoh et al demonstrated that tadalafil improved the bladder blood flow and increased the level of $8-\mathrm{OHdG}$ in tissue (14). Tadalafil has also been reported to show anti-inflammatory activity in the prostate and might be a prevention effect from prostate cancer $(15,16)$.

The limitations of this study include no staining in completely normal prostatic tissue. Further studies, using normal prostate tissues and/or cell lines, are also required to reveal the underlying mechanism for the involvement of 8-OHdG in prostate carcinogenesis and cancer progression.
Table I. First and second antibody for immunohistochemistry analysis.

\begin{tabular}{|c|c|c|c|}
\hline \multicolumn{2}{|l|}{ Name } & Cat. no. & Company \\
\hline \multicolumn{2}{|c|}{$\begin{array}{l}\text { 8-Hydroxyguanosine } \\
\text { polyclonal antibody }\end{array}$} & $\mathrm{ab} 48508$ & Abcam \\
\hline \multicolumn{2}{|c|}{$\begin{array}{l}\text { Second antibody and staining kit } \\
\text { Histostain-SP kit }\end{array}$} & $95-9943$ & Invitrogen \\
\hline \multicolumn{4}{|c|}{$\begin{array}{l}\text { Table II. Immunohistochemical staining of 8-hydroxyguano- } \\
\text { sine }(\mathrm{P}<0.01) \text {. }\end{array}$} \\
\hline $\begin{array}{l}\text { Immunoreactive } \\
\text { score }\end{array}$ & $1+$ & $2+$ & $3+$ \\
\hline $\begin{array}{l}\text { Prostate } \\
\text { adenocarcinoma }\end{array}$ & $0(0.0 \%) 0(0.0 \%)$ & $3(30.0 \%)$ & $7(70.0 \%)$ \\
\hline $\begin{array}{l}\text { Non-neoplastic } \\
\text { tissue }\end{array}$ & $0(0.0 \%) 0(0.0 \%)$ & $50(71.4 \%)$ & $20(28.6 \%)$ \\
\hline
\end{tabular}
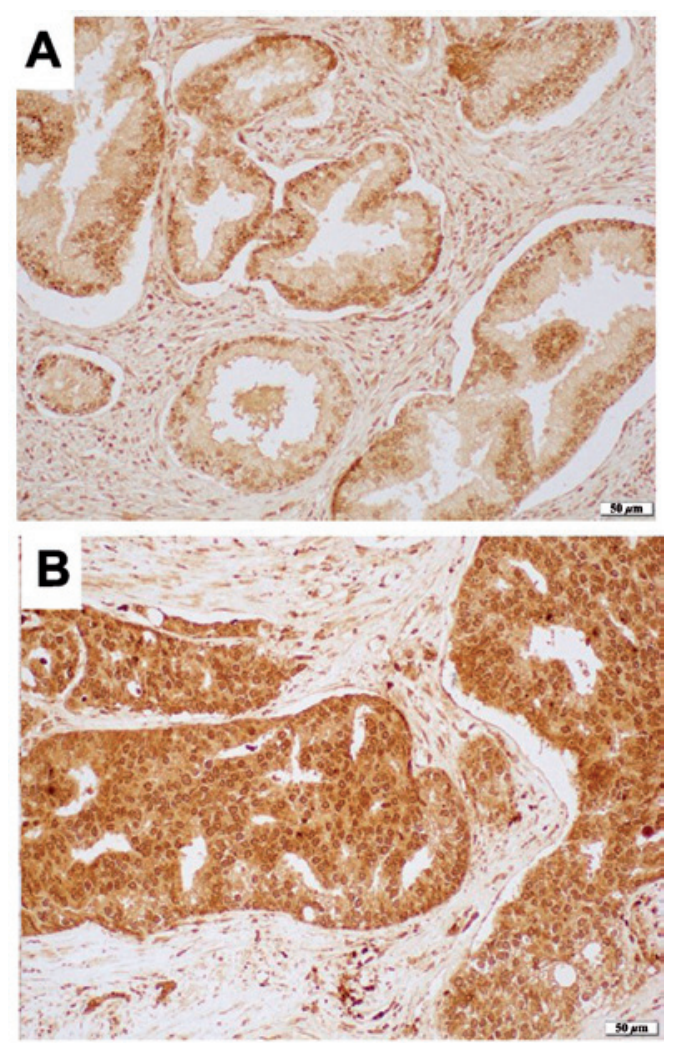

Figure 1. Immunohistochemistry of 8-hydroxyguanosine. Strong and moderate expression was observed in (A) non-neoplastic prostate and (B) prostatic adenocarcinoma tissue specimens, respectively.

We found that 8-OHdG expression was elevated in prostate cancer tissues compared with non-neoplastic prostate tissues. 8-OHdG may therefore play an important role in prostate cancer development. 


\section{Acknowledgements}

Not applicable.

\section{Funding}

Funding was received from Kakenhi grants (grant no. 16K20152) for the Ministry of Education, Culture, Sports, Science and Technology of Japan.

\section{Availability of data and materials}

The datasets used and/or analyzed during the current study are available from the corresponding author upon request

\section{Authors' contributions}

SO, TK and HU conceived and designed the experiments. SO, TK, YI, TT, SK, KI, HM and HU performed the experiments. SO, TK and HM wrote the manuscript. All authors have read and approved the manuscript

\section{Ethics approval and consent to participate}

Not applicable.

\section{Patient consent for publication}

Not applicable.

\section{Competing interests}

The authors declare that they have no competing interests.

\section{References}

1. Cai H and Harrison DG: Endothelial dysfunction in cardiovascular diseases: The role of oxidant stress. Circ Res 87: 840-844, 2000.

2. De Nunzio C, Aronson W, Freedland SJ, Giovannucci E and Parsons JK: The correlation between metabolic syndrome and prostatic diseases. Eur Urol 61: 560-570, 2012.

3. Sychlowy A, van der Gaag $\mathrm{H}$ and Hannen-Hofheinz I: Hyperkalemia-life-threatening early complication of asphyxia in premature infants. Monatsschr Kinderheilkd 138: 62-65, 1990 (In German).
4. Saito M, Tsounapi P, Oikawa R, Shimizu S, Honda M, Sejima T, Kinoshita Y and Tomita S: Prostatic ischemia induces ventral prostatic hyperplasia in the SHR; possible mechanism of development of BPH. Sci Rep 4: 3822, 2014.

5. Shim V, Gauthier ML, Sudilovsky D, Mantei K, Chew KL, Moore DH, Cha I, Tlsty TD and Esserman LJ: Cyclooxygenase-2 expression is related to nuclear grade in ductal carcinoma in situ and is increased in its normal adjacent epithelium. Cancer Res 63: 2347-2350, 2003

6. Miyake H, Hara I, Kamidono S and Eto H: Oxidative DNA damage in patients with prostate cancer and its response to treatment. J Urol 171: 1533-1536, 2004.

7. Nelson WG, DeWeese TL and DeMarzo AM: The diet, prostate inflammation, and the development of prostate cancer. Cancer Metastasis Rev 21: 3-16, 2002.

8. Kanwal R, Pandey M, Bhaskaran N, Maclennan GT, Fu P, Ponsky LE and Gupta S: Protection against oxidative DNA damage and stress in human prostate by glutathione S-transferase P1. Mol Carcinog 53: 8-18, 2014.

9. Koul HK, Kumar B, Koul S, Deb AA, Hwa JS, Maroni P, van Bokhoven A, Lucia MS, Kim FJ and Meacham RB: The role of inflammation and infection in prostate cancer: Importance in prevention, diagnosis and treatment. Drugs Today (Barc) 46: 929-943, 2010

10. Wu Q and Ni X: ROS-mediated DNA methylation pattern alterations in carcinogenesis. Curr Drug Targets 16: 13-19, 2015.

11. Raza Y, Khan A, Farooqui A, Mubarak M, Facista A, Akhtar SS, Khan S, Kazi JI, Bernstein C and Kazmi SU: Oxidative DNA damage as a potential early biomarker of Helicobacter pylori associated carcinogenesis. Pathol Oncol Res 20: 839-846, 2014.

12. Fukumoto K, Nagai A, Hara R, Fujii T and Miyaji Y: Tadalafil for male lower urinary tract symptoms improves endothelial function. Int J Urol 24: 206-210, 2017.

13. Yokoyama O, Ozeki A, Suzuki N and Murakami M: Early improvement of storage or voiding symptoms by tadalafil predicts treatment outcomes in patients with lower urinary tract symptoms from benign prostatic hyperplasia. Int J Urol 25: 240-245, 2018.

14. Gotoh D, Torimoto K, Tatsumi Y, Hori S, Yamada A, Miyake M, Morizawa Y, Aoki K, Tanaka N, Hirayama A, et al: Tadalafil, a phosphodiesterase type 5 inhibitor, improves bladder blood supply and restores the initial phase of lower urinary tract dysfunction in diabetic rats. Neurourol Urodyn 35: 444-449, 2017.

15. Vignozzi L, Gacci M, Cellai I, Morelli A, Maneschi E, Comeglio P, Santi R, Filippi S, Sebastianelli A, Nesi G, et al: PDE5 inhibitors blunt inflammation in human BPH: A potential mechanism of action for PDE5 inhibitors in LUTS. Prostate 73: 1391-1402, 2013.

16. Zarifpour M, Nomiya M, Sawada N and Andersson KE: Protective effect of tadalafil on the functional and structural changes of the rat ventral prostate caused by chronic pelvic ischemia. Prostate 75: 233-241, 2015. 